\title{
Controllability of Technosphere and Paradigm of Global Evolutionism
}

\author{
Natalia Popkova \\ Doctor of Philosophical Sciences, Professor, Bryansk State Technical University \\ (Bryansk, Russia) \\ E-mail: npopkova12@rambler.ru \\ ORCID: 0000-0003-2889-4926
}

The article analyzes the modern philosophical view of technique as the next step in the selfdevelopment of the universe, and shows its relevance for the analysis of problem of the controllability of technosphere. The applicability of various philosophical approaches to the analysis of technique for examining contemporary global problems is considered. Philosophy of technique, analyzing technogenic processes in nature and in society, offers various philosophical approaches, on the basis of which programs are developed to overcome the current civilizational crisis. It is shown that there are different views on its nature: the theoretical models obtained and the practical recommendations depend on the understanding of the technique. The traditional view of technique as a passive tool is not effective enough as a basis for philosophical analysis. An alternative concept is disclosed that understands technical progress as a stage of global evolution; its advantages and disadvantages are analyzed. Developed by modern science, the concept of global evolutionism allows us to see the similarity between the processes of nature change, characteristic for living matter and for technical reality. If we consider, as an evolutionary criterion, the scale of processing information or the ability to adapt, then technique stands at a higher stage of development than biological life. The self-organization of the global technical system has not yet been achieved and the formation of the artificial intelligence controlling it has not been completed, but humanity is actively working in this direction, confident that the emerging technosphere is just a tool for improving its well-being. The development of the evolutionary approach to technique leads to the conclusion that the problems of modern humanity are signs of the beginning of his involution, caused by the transition of evolutionary leadership to technical reality. The technique is already emerging from the power of man: perhaps attempts to preserve the former person or nature are opposed to the vector of evolution leading them to become elements of the technosphere. Although this approach does not take into account a number of modern concepts (sustainable development, controlled evolution, etc.), evolutionary approach to technique requires further analysis and development of a methodology for its verification and the derivation of possible recommendations for environmental performance. It is concluded that further philosophical search is necessary, since different views on technique serve as a basis for opposing programs to exit from the current environmental crisis. Change of ideas about the essence of technique leads to new, unexpected prognosis of the development of technogenic society and helps to take a fresh look at the prospects of achievement of the controllability of technosphere.

Keywords: technique, technosphere, evolution, nature, humanity, management, philosophy, Universal (global) evolutionism

Received: January 22, 2018; accepted: May 10, 2018

(C) Popkova, Natalia, 2018 
Philosophy and Cosmology, Volume 21, 2018: 21-31

DOI: $10.29202 /$ phil-cosm/21/3

\section{Introduction}

For several decades the scientific community proposes the programs of nature protection, despite it there are no significant results in the sphere of the prevention of the negative results of the industrial growth, which is explained by the fact the programs are not substantiated enough theoretically. The majority of the researchers explain the modern global problems by the acceleration of the technical progress and the uncontrollable growth of the technosphere created by it [Bazaluk, 2014; 2016; Krichevsky, 2016; Nazaretyan, 2015; Ursul, 2015; Yablokov et al., 2015; 2016; 2017].

There is stated the controllability of technosphere lack and concluded that it is the cause of man-caused crises; there are offered various concepts explaining the necessity and possibility of control over the technical reality evolution [Krichevsky, 2015], but they are all criticized. There is observed, that although the technosphere is the society material basis, it is controlled not so much by people's will, but, according to Vadim Rozin by "the internal logic of the technology development itself" [Rozin, 2017: 110]. Therefore, as Sergey Krichevsky states, "in the $21^{\text {st }}$ century the priority and key issue is the controllability of technosphere evolution, which is a part of the evolution control overall problem" [Krichevsky, 2017a: 155].

\section{Problem Statement}

Technosphere is an artificial environment created by the society; in recent centuries, according to Sergey Krichevsky, "the process of its evolution has been accelerating and expanding the Earth and space" [Krichevsky, 2017a: 156]. Technosphere is "a supercomplex, global, rapidly and nonlinearly developing object with contradictory properties, including self-development, selfregulation and the properties of a powerful generator and civilization development multiplier." We have to admit that "at the present time there is the lack of necessary knowledge, technology and material resources for the full-scale effective technosphere control" [Krichevsky, 2017a: 158-159]. It "also objectively exists and develops as an artificial autonomous global system of technical reality beyond the Earth biosphere" [Krichevsky, 2017a: 156]. As a rule, modern technogenic problems are explained by the fact that the technosphere formation "continues in the unstable mode of accelerating nonlinear development and spatial expansion". In this artificial environment "there is the lack of internal and external communication, including feedback, which is necessary for the balanced development": in Sergey Krichevsky's opinion, "these are the main causes of technosphere "uncontrollability" [Krichevsky, 2017a: 157]. To solve modern problems, to ensure the mankind's sustainable development, it is necessary "to create a balanced and stable biotechnosphere/technobiosphere in the socio-techno-natural paradigm" [Krichevsky, 2017a: 157]. The possibility of returning the controllability of technosphere is justified "with the application of the anthropic principle and its "active" super (post) anthropic supplement": "The space humanity has the evolutionary purpose to actively control the evolution: to change the person, mankind and the Universe" [Krichevsky, 2017b: 51]. This controllability is necessary to prevent human civilization global catastrophe, to take control of the technical reality and technical development" and in particular, "to preserve the Earth biosphere, its biodiversity and sustainability as a single global ecosystem" [Krichevsky, 2017a: 157]. 
Any specific historical technical complex, although determined by the economic norms and socio-cultural rules, is not given by them unambiguously. In particular, natural environment degradation and the instrumental rationality expansion were hardly the goals of anyone's technical activities: but, since these processes take place, there is logically presented their interpretation as the self-developed technosphere. Thus, there is the following insufficient controllability of technosphere:

1. Technological process incomplete controllability (not always people manage to achieve the desired change of technical systems);

2. Incompleteness of forecasting the consequences of introducing technical innovations (in addition to positive results there are always negative, they can be reduced, but it is impossible to eliminate them);

3. The need for sociocultural support for implementing technological processes, which leads to the social environment change.

It is necessary to find the cause of our inability to control the technical reality to understand the way to return to its controllability. The philosophy of technique can assist in this study.

Philosophical reflection can help during the methodological analysis of the proposed ways of surmounting the civilization crisis in particular, clearing out and articulating the unperceived principles and values put in them [Popkova, 2010: 7-38]. Among the problems demanding methodological working out a significant place is occupied by the clearing out of the terminology, in particular, the central term of this sphere "technique" as it is possible to see does not have a conventional meaning and different philosophical approaches input different content in it [Popkova, 2014c: 7-21]. The traditional view on technique, which is in the basis of the majority present conceptions, does not take into consideration the observed aspects of the technical activity, which causes practical difficulties.

The usual (based on common sense) understanding of technique:

1. Understands as technique the unity of devices and technologies created by people to make easier the processes of converting nature and satisfying their needs (man is the final result of the evolution, the only sentient being on the Earth having the opportunity of self-development and creating artificial environment, because of it man uses and converts other natural objects);

2. Thinks that the sentient influence of the people is possible on all the parameters of technical reality (nature is subordinate to the laws that can be discovered by people and used for improving the quality of their life);

3. States that the difference between natural and technical objects is apparent (for example, natural systems can develop themselves on account of the substance and energy from the environment and technical devices can only ruin without the influence of man);

4. Dually evaluates the influence of technique on the environment (on the one hand man has the right to influence and to change nature because as the possessor of mind he is the superior creature on the earth, on the other hand the uncontrollable consumption of natural resources and the pollution of the environment incurs harm to humanity);

5. Arrives at the conclusion that technical and cultural forms of activity are a breach of the natural order of things, a distortion of biological processes (saying nature we mean the pre-human step of development of the biosphere including the forms of life and perception, which do not have any mind). 


\section{Purpose of the Study}

So technique and nature are opposed by the traditional conception, man is declared to be the only creator of technique and it is the obedient instrument of a man, the continuation and supplement of his organism. So, man is the active subject, nature is the passive object, technique is an instrument (an intermediary active with respect to nature and passive with respect to man): here there are the main theses of the traditional understanding of technique. Upon the whole the growth of technosphere is perceived positively as the aspect of the united process of overcoming of the spontaneity of nature and the human soul - the change of the spontaneous processes of self-regulation by the system of efficient, rationally created practices [Popkova, 2014c: 311-312].

The nature-protection activity is justified here by the interests of people but not of nature and other living creatures. The mistakes of man exploiting nature for direct mercenary interests and depriving the future generations of the favourable environment are considered to be the reason of the modern technogenic crisis. Therefore, it is necessary to restore the control of economic and ecological processes by planning scientifically the technological activity [Popkova, 2014c: 299-302].

What are the flaws of this conception? First, it uses the ideas created within the framework of the mechanistic picture of the world and it does not take into consideration the theory of complicated systems worked out in the $20^{\text {th }}$ century. Second, it cannot find the objective reasons of technological problems and give the global program of their overcoming. Therefore, the naturalist or instrumental conception of technique is unacceptable, as Vadim Rozin states correctly: after the scientific and technological revolution, it is necessary to understand technique not as the means of production but as the manifestation of intellectual and sociocultural processes [Rozin, 2012: 180].

Therefore, the habitual ways of categorizing technique require rethinking and the creation of concepts revealing its essence. Unfortunately trying to overcome the limitation of the traditional model many defenders of nature prefer to criticize technique and technogenic transformations of nature and technical attitude to the world, they see in technical reality something unnatural, the distortion of nature and the changes introduced by technique are declared inadmissible and harmful in advance [Popkova, 2014a: 250-260]. At that, philosophical analysis of technique finishes and publicist literature begins — the denouncement of modern civilization. Some investigators pay attention to categorical and methodological analysis of this multiple phenomenon: but following the opinion of Vadim Rozin, the generally accepted definitions of technique are "mechanistic if not contradictory with respect to ideas" giving only some illusion of the explanation. To get a multiple idea of it is necessary to analyze the proposed discourses and conceptions namely "disputes about technique and its essence" [Rozin, 2006: 7-8].

\section{Discussion}

Philosophy offers non-traditional interpretations of the technique essence, which claim to identify the causes of its controllability lack. For example, the technosphere is analyzed as the society subsystem, in the context of its evolutionary potential: in this case, the person's inability to predict the technical development results is a particular manifestation of our inability to control our social development.

For example, Vadim Rozin considers the technical reality to be the type of social reality including social machines "created by civilization designed for solving certain conflicts and 
for organizing social processes". The term "machine" must emphasize that social institutes are "special technique" for providing the organization conditions of "technological means" of solving social problems [Rozin, 2012: 186]. This view on technique is opposed by Vadim Rozin to traditional "scientific-engineering" picture of the world, in which it was considered that the technique "does not influence man because it is the means of man and nature (is written using the language of mathematics) and contains the laws on the basis of which technique can function". Now we can acknowledge that this idea does not correspond to reality: technique changes both nature and man. But it is not easy to change the obsolete picture of the world because behind it there are social institutes and the cultural type of the modern man, for whom all the processes are "realized, manifested and articulated with the framework of technogenic discourse" [Rozin, 2012: 192-194]. Not only "the average man" who as "a social individual is completely caused by the images and values of technogenic civilization" shares the standard attitude "but also those, from whom the development of modern technology depends including authorities, specialists and experts", they do not try to reverse the course of the events and "think within the framework of technogenic civilization" [Rozin, 2006: 223-226]. So, Vadim Rozin arrives at the conclusion that it is possible to change the character of the development of technique but it "will require from a man such big changes (in the sphere of his values, way of living, in his practices), that will mean the gradual departure from the modern civilization and practically an attempt to create a new civilization". This new civilization will also be based on technique but of another type "more safe for life and development of humanity" [Rozin, 2006: 248-249]. People of the future will have to create new morals and to change the character of their activity changing the habitual scientific and engineering picture of the world with "new ideas of nature, technique, ways of solving tasks, worthy life of a man" [Rozin, 2006: 246].

Technique can be characterized as "natural-artificial" reality, depending on the human activity but which is not its product. On the one hand, activity is the condition of the existence of technical reality providing its reproduction and development. On the other hand, technical reality precedes the activity of each man being its condition (together with social institutes). The main problem is that studying technique is not objective and disinterested, it is done with a concrete purpose when the researchers want to get not only the laws of the technical reality but the possibility to effect its development to solve the "crisis caused not only by technique but by technique too." Studying technique, as Vadim Rozin considers, demands to understand it "as the moment of this ill-being" and to remember about the main purpose — the development of the methods of solving the crisis so "the idea of limiting the extensive development of technique... the concept of creating principally new technique, so such one, with which both man and society can agree, which provides their safe development and existence" [Rozin, 2006: 6-7].

As we can see within the framework of one of the new models technique as a type of social practices is regarded and the overcoming of the technogenic problems requires the improvement of society in the direction of its humanization. Other philosophical conceptions are worked out proposing different understanding of the essence of technique. In connection with modern scientific tendencies, the philosophical approach is formed considering equipment as natural, intrinsic phenomenon: the result of the regular self-development of the Universe.

Now the conception of the global evolutionism dominates in science postulating natural appearance and emerging of all the objects and systems, from the Universe to human society [Bazaluk, 2014, 2016; Ursul, 2014, 2018; Yablokov, 2016: 166-169]. The ideas about the succession of the origin of the Solar system and the Earth, the origin of the biological species and the formation of biological species were developed by many scientists who were able to see the complication of those systems, so the increase in the level of their organization. Now 
from the description of the facts science switched to a single theoretical model acknowledging the presence of the evolution process of the cosmic scale: successively the generation of one structural level (having principally new characteristics) from another one takes place [Popkova, 2010:71]. However, the intuitive supposition about the existence of this model became a scientific paradigm only when the methods of studying evolving objects were developed. The attempt to comprehend the evolution process was finished by the understanding of the development of the Universe as the self-organization of complicated systems: the formation of each new type of stable structures is understood as a stage of evolution. Within the framework of post-non-classic science, the principle of evolution becomes the basic one: uniting the processes of movement and changing characterizing the processes of birth and creation the unitary global evolution process correlates between each other the fundamental levels of the substance organization as the elements of unity of the Universe [Popkova, 2010: 119-134]. Post-non-classic science declares: "Evolution has a through character, it passes on all the hierarchical levels of the world organization: cosmic evolution, prebiotic evolution, the evolution of wildlife, anthropogenesis, human history..." [Knyazeva, 2015: 92]. In particular, within the framework of this conception it is clear while local ecological measures do not solve the global problem of preserving nature: to improve the state of the environment locally it is inevitably necessary to take resources again from a wider system- the biosphere.

For the modern evolution paradigm [Popkova, 2014c: 315-317]:

1. The universe is a self-developing system, in which there is a vector of growth and complication (the development of nature is self-organization or evolution, an increase of the degree of organization of the Universe and its parts);

2. The ability of man to change the world rationally and technologically appeared during the self-organization of the cosmic system and therefore also has some evolution potential because of it his technical activity is approved (it is considered that man as the creator of the artificial world is not an exception among the living creatures but a continuator of the global tendency of the perfection of biosphere transforming the inanimate substance of the planet);

3. The paradigm of the self-organization excludes such a category as "artificial" (everything in the Universe is caused by the united process of the complication of the system even if living creatures are the intermediate reason) and it sees in the technical change of nature the increasing speed and the scales of some type of the biogenic flow of atoms, and the man is an intermediary through whom this natural change of rates happened;

4. Together with consciousness and mind people develop during evolution the possibility to do things which on the lower levels of evolution happened due to blind laws or instincts - to realize the new states of material objects (changing nature using technical means);

5. Technique (created on the basis of that ability) does only what man requires from it, and the absence of its control now is the result of the gap between the intellectual development of the people and the technical one (now there is a gap between the material rapidly developing technologies and culture, which remains on the previous level).

The representation of the technical reality as a stage of self-development of the Universe has some heuristic potential. Technical reality is considered as a complicated self-organizing system, in which the main role is played not by the external influences (including the purposeful activity of man) but by the adaptive processes (having the purpose of solving 
problems, which appear during the interaction of the elements of the system) [Popkova, 2014c: 218-230]. Here saying "technique", we understand the means and methods created by man for converting material objects and of getting substance, which cannot be reproduced extra-technically. Technical progress is presented as techno-evolution controlled by laws of nature relatively autonomous from the will of man and social factors [Popkova, 2014c: 136138]. So, the universal conception of an evolving system can be made on the basis of the analysis of technique.

As we can see, the new philosophical models of technique and technical development claim to identify the causes of the technosphere low controllability: unlike traditional understanding, they point to the evolutionary potential of technique development, going beyond the limits of human goal-setting.

The advent of new theoretical models of technique has not only philosophical interest: by the words of Vadim Rozin, "conceptualization is the essential characteristic of the idea of technology" [Rozin, 2017:137], because it is the basis for creating practical programs.

As the sociological dependency of technique is discussed in detail in Vadim Rozin's publication [Rozin, 2017], let us pay attention to the techno-evolution vision and consider the resultant practical guidelines. They have already been formulated by the philosophy of technique and met with mixed reactions. They were even condemned for technical expansion justification. We will outline the main principles of the evolutionary understanding of technique.

The tradition going back to Russian cosmism treats the human mind as the new leading factor of the evolution of the Universe and the technique as an obedient instrument for realizing this purpose [Moiseev, 1999; Vernadsky, 1997]. This tradition states that people (and sentient beings) are the future leaders of the evolution, the saviours of the biosphere from its imminent extinction. The mind will help to overcome the destruction of the outer space (cosmos) because of entropy and to bring life to the borders of the Universe. Because of its people must not be subordinate to nature (doomed to die because of natural laws) but they must improve it prolonging its existence. Technical progress is seen here not as a mistake of historical development but as an instrument of evolution. However, man despite the fact that he became the main geological force does not understand his planetary responsibility, as the result of which ecological difficulties appeared; when the conscience of people reaches the level necessary to control their own technique they will begin to perfect nature. The progressist optimism of this conception is deservedly criticized [Popkova, 2014a: 71-82]. Some philosophers suspect this idea of justifying predatory nature using. Therefore, Vladimir Kutyrev warns that "universal evolutionism, which is the paradigm of fundamental science... deprives of any independent status any existing form of life. They are considered as some means and a factor of the further development... The present is only "the spring-board" for the future" [Kutyrev, 1998: 11].

However, this concept can be followed by other conclusions, pessimistic, denying the opportunity to return the controllability of technosphere.

Considering the techno-evolution as a natural process and proclaiming technical reality as the new level of the self-organization of the Universe it is possible to continue the chain of the discourse and to put forward a hypothesis that technical reality is a higher evolution level than the biological one and the modern civilization crisis is accompanied by the technical progress not by chance. First, the provision typical for modern natural science that "any form of life including the social one will finish once giving birth to other forms of life" [Rozin, 2017: 139] is perceived in a new way. Probably the essence of the crisis is that man (and broader the biological world) has lost the evolution leadership and begins its involution 
and the modern problems are the sign of it. The tendency of the evolution naturally causes the advent of new, more complicated objects and systems (cosmogenesis, biogenesis, sociogenesis); probably the following one, on which the preservation and the increment of information will take place non-biologically. Does this model reflect the reality? It correctly notes some of the current trends, but ignores the processes of ecological technologies and activities (clean, environmentally friendly and «green» technologies) and does not take into account their potential for harmonizing human relations with the biosphere [Krichevsky, 2015, 2018; Ursul, 2017; Yablokov, 2015: 110-114; Yablokov, 2017: 74-78].

\section{Results}

Therefore, the conclusions from the evolutionary concept of technique are as follows. Humanity (as the subsystem of biosphere) has achieved such a progressive (for evolution) characteristics as self-organization, self-regulation, self-renovation. Apparently, the new, higher level of life must have not lower degree of them having at the same time the ability for selfreproduction. What existing thing can perform the role of reality, which is more complicated and performs the conversion of the outer environment into the internal one, "artificial"? Only technical reality! In modern world, only technique can have all the features of a developing subsystem: it increases its interconnection and interrelationship increasing the speed of converting information and its autonomy from the environment. Only the degree of the selforganization achieved by technique can give rise to doubts. However, naïve understanding of technique as an obedient mechanism forces people to perfect it making closer the transition from biological evolution to spontaneous technical one. Probably man is not only the possessor of mind who appeared as the result of biological processes on the biological basis but the means for achieving a higher level of space, the creator of the new level of reality - the technical one? The technical activity of man can be evaluated as the perfection of the biogenic flow of atoms which in the framework of the self-development of the Universe (the acceleration of the conversion of natural resources and the increasing of its scale). Probably man not only uses nature, but also nature uses him for another step of evolution? The globalization of the government of the humanity forms the structural analogy of the brain missing in the technosphere and the central nervous system: the power of the connections between the local technical complexes overbalances the contradictions between them. Therefore, the well-formed new understanding of technique as the new step of self-organization of the Universe requires to acknowledge that biological life and human mind functioning on its basis is a parting step, which has used up its evolution potential. This conclusion seems to be shocking but the logic development of the theses of global evolutionism.

According to this concept, the development of one of the subsystems of the biosphere happens on account of the degradation of other subsystems: the development of humanity on account of nature and the development of the technique on account of humanity. The evolution in nature is connected with involution: if the system upon the whole increases the degree of its being organized increasing its variety then some of its subsystems regress become more simple decreasing the degree of their organization. The involution of the system, the process of its simplification and of the return to simpler forms is the logical result of the self-regulation of a bigger system, the mechanism of its conversion into a new regime of functioning. There are several global problems for modern humanity: many changes of social, economic, spiritual bases of the life of people can be interpreted as the signs of degradation. The variety of social and cultural models is disappearing: mass culture is a powerful means of uniting behaviour. Probably the modern epoch is the transition from the 
evolution potential of humanity to technique. It is not the biosphere that develops but the system of a higher level - Universe and the biosphere, and humanity have fulfilled their task and they are passing away.

So the evolution approach to the analysis of technique

1. Considers the modern epoch as another regular stage of the global evolution within the scale of the planet it consists in the concentration of the evolution potential on the level of the technical reality on account of the involution of the objects of the previous levels - biological and social ones (evolution progress does not stay at the same place and after the most developed level now it prepares the advent of another level of the organization of substance - more capable for expansion and the increased conversion of information, which will make the other ones subordinate to itself).

2. Sees in it an objective process, the tempos of which are subjective (because the selforganization of the technical system has not been achieved yet and the creation of the artificial intelligence controlling it has not been finished).

3. Considers the ecological and social and cultural crisis to be natural (the universalization and standartization of the individual and national being, the levelling of the personal element and the suppression of it by social and cultural processes - it all can be evaluated as the sign that the self-development of the humanity is not maintained by the laws of evolution).

4. Rejects as fruitless the dreams of man about the eternal domination over nature based on the acknowledgement of his "perfection" (technique are quitting the power of man - he is loosing physically and mentally the ability to control technological processes and therefore to control them).

5. Makes the conclusion that the preservation of the former man contradicts the vector of evolution bringing him to the conversion in an element of the technosphere (social progress has become the means for deploying technologies - the technological renovation is done automatically, but the cultural and moral norms remain behind the accelerating transformations).

\section{Conclusion}

Therefore, the analysis of the concept under consideration allows us to draw a number of practical conclusions. Probably man will be able to prevent this future if he does not rely on natural processes (that "play" now against people and that aim not at the creation of new forms of social-and-cultural life but at their levelling) but will remember that social systems differ from other ones (nonorganic ones and organic ones) because they include people having consciousness and will and because of it, the self-organization in them is supplemented with a voluntary organization. If the processes destructive for humanity become natural, it is necessary to interfere in them actively. Co-evolution with biosphere advertised by the followers of nature protection will result in the extinction of it and of humanity. It is necessary to develop the plans of slowing down "natural" processes [Popkova 2014b: 294-299]. There is a variability of development: the evolution vector in some spheres of space (cosmos) can become slower, asymptotically tending to zero (for example, living substance appeared not in all the Universe). The concept of controlled evolution of biosphere is being developed [Yablokov, 2017: 64-73]. Monitoring the alarming tendencies, we can realize undesirable processes for us and act on them in some points.

It is necessary to remember about the relative precision of any theoretical model: "Principally any system can be described both as natural and as artificial. A system from the natural point of 
view is considered as a self-moving mechanism developing following its internal laws... From the artificial point of view a system is considered as a mechanism constructed from outside" [Gorokhov, 2007: 125]. We have the right to consider technique in its interaction with nature as an artificial phenomenon and in its contact with a man as natural: but far reaching predictions will be a useful abstractions like many mathematical models.

Therefore, modern philosophy of technique proposes different variants of its understanding on the basis of which philosophical approaches are worked out.

The philosophical study of the technosphere controllability problem allows making the following conclusions. Because the traditional instrumental understanding of technique has shown its insufficient efficiency while analyzing global problems, conceptions considering equipment from the side of its social causality or its position in the evolution picture of the world have the biggest potential. If the traditional understanding of the technique essence does not even allow raising the question of the evolution control lack, the new approaches proposed by the philosophy of technique show the inevitable problems. Whether the uncontrollability of technosphere is explained by its social dependence or evolutionary potential, in any case there is required serious sociocultural transformation from the mankind to take their own development and evolution of technical reality under control. At the modern level of ideological and social development this problem solution unfortunately seems unattainable.

\section{References}

Bazaluk, Oleg. The Theory of Evolution. Philosophy and Cosmology. Volume 15, 2014: 25-33. Bazaluk, Oleg. The Theory of Evolution: From a Space Vacuum to Neural Ensembles and Moving Forward. Cambridge Scholars Publishing, 2016. — 170 p.

Bazaluk, Oleg and Denys Svyrydenko. Philosophy of War and Peace: In Search of New European Security Strategy. Anthropological Measurements of Philosophical Research, 12, 2017: 89-99.

Gorokhov, Vitaliy. Basis of the philosophy of technique (Osnovy philosophii tekhniki i tekhnicheskikh nauk): Textbook. Moskva: Izdatelstvo Gardarika, 2007 (in Russian).

Knyazeva, Elena. Universal evolutionism: patterns, which tie (Universalniy evolyutsionizm: patterny, kotorye svyazyvayut). Filosofskie nauki. \#3, 2015: 90-103 (in Russian).

Krichevsky, Sergey. A Management Concept of the Technosphere's Evolution (Kontseptsiya upravleniya evolyutsiey tehnosfery). Philosophy and Cosmology. Vol. 18, 2017a: 153164 (in Russian).

Krichevsky, Sergey. Cosmic Humanity: Utopia, Realities, Prospects (Kosmicheskoe chelovechestvo: utopii, realii, perspektivy). Future Human Image. Vol.7, 2017b: 50-70 (in Russian).

Krichevsky, Sergey. Evolution of technologies, "green" development and grounds of the general theory of technologies (Evolutsiya tekhnologij, "zelenoye" razvitie i osnovaniya obshchej teorii tekhnologij). Philosophy and Cosmology. Vol. 14, 2015: 120-139 (in Russian).

Krichevsky, Sergey. New model of evolution of technologies and prospects of research with using Big Data. Philosophy and Cosmology. Volume 17, 2016: 118-135.

Krichevsky, Sergey. Super Global Projects and Environmentally Friendly Technologies Used in Space Exploration: Realities and Prospects of the Space Age // Philosophy and Cosmology, Volume 20, 2018: 92-105.

Kutyrev, Vladimir. Love of wisdom on the eve of new century (Lyubov' k mudrosti na poroge novogo veka). Vestnik MGU. Filosofiya. 3, 1998: 3-16 (in Russian). 
Moiseev, Nikita. Reflection on the noosphere - humanism in our time. In The Biosphere and Noosphere Reader-Global Environment, Society and Change. London, New York: Routledge, 1999.

Nazaretyan, Akop. Mega-History and the $21^{\text {st }}$ century singularity puzzle. Philosophy and Cosmology. Volume 15, 2015: 84-98.

Popkova, Natalya. Anthropology of technique. Emerging (Antropologiya tekhniki. Stanovlenie). Moskva: Izdatelstvo LIBROKOM, 2014a (in Russian).

Popkova, Natalya. Introduction into the metaphilosophy of technique (Vvedenie v metaphilosophiju tekhniki). Moskva: Izdatelstvo LENAND, 2014b (in Russian).

Popkova, Natalya. The philosophy of technosphere (Filosofiya tehnosferyi). Moskva: URSS, 2014c (in Russian).

Popkova, Natalya. The philosophy of ecology (Filosofskaya ekologiya). Moskva: URSS, 2010 (in Russian).

Rozin, Vadim. The idea and modern conceptions of technique (Ponyatie i sovremennyie kontseptsii tehniki). Moskva: IFRAN, 2006 (in Russian).

Rozin, Vadim. Technique and social reality: philosophical reflections and conceptions. (Tehnika i socialnost: philosophskije razlichenija i kontseptsii) Moskva: Izdatelstvo LIBROKOM, 2012 (in Russian).

Rozin, Vadim. The technology as the challenge of time (studying, idea and types of technology (Tekhnologiya kak vyzov vremeni (izuchenie, ponyatie i tipy tekhnologiy)). Philosophy and Cosmology. Vol. 19, 2017: 133-141 (in Russian).

Ursul, Arkady. Cosmoglobalistics: Interrelation of Global and Cosmic Processes (Kosmoglobalistika: vzaimosvyaz globalnyh i kosmicheskih protsessov). Philosophy and Cosmology. Volume 12, 2014: 90-118. (in Russian)

Ursul, Arkady, Tatiana Ursul and Mideg Dugarova. New Goals of Sustainable Future. Philosophy and Cosmology. Volume 18, 2017: 37-50.

Ursul, Arkady, and Tatiana Ursul. Towards a global sustainable future. Philosophy and Cosmology. Volume 16, 2015: 110-160.

Ursul, Arkady and Tatiana Ursul. Universal (Global) Evolutionism. Philosophy and Cosmology, Volume 20, 2018: 33-41.

Vernadsky, Vladimir. Scientific Thought As a Planetary Phenomenon. Moscow: Nongovernmental Ecological V.I. Vernadsky Foundation, 1997.

Yablokov, Alexey, Vladimir Levchenko and Anatoly Kerzhentsev. Essays of biospherology. 1. There is a way: the transition to a managed evolution of the biosphere (Ocherki biosferologii.1. Vyihod est: perehod k upravlyaemoy evolyutsii biosferyi). Philosophy and Cosmology. Volume 14, 2015: 91-117. (in Russian)

Yablokov, Alexey, Vladimir Levchenko and Anatoly Kerzhentsev. Essays of biospherology. 2. The biosphere as a living system. Peculiarities of the evolutionary process on the biosphere level (Ocherki biosferologii. 2. Biosfera kak zhivaya sistema. Ob osobennostyah evolyutsionnogo protsessa na biosfernom urovne). Philosophy and Cosmology. Volume 17, 2016: 152-176. (in Russian)

Yablokov, Alexey, Vladimir Levchenko and Anatoly Kerzhentsev. Essays of biospherology. 3. The Biosphere as a Living System. On the Harmonization of Human and Biosphere Relationship (Ocherki biosferologii. 3. Biosfera kak zhivaya sistema. O garmonizatsii vzaimootnosheniy cheloveka i biosferi). Philosophy and Cosmology. Volume 18, 2017: 52-83. (in Russian) 